\title{
The effectiveness of a counseling program based on Mindfulness in increasing concentration of attention and Reduce psychological stress among the general secondary stage
}

\author{
Prof. Adel M. ElAdl ${ }^{1}$ \\ Prof. of Educational Psychology \\ Faculty of Education - Zagazeg \&Sultane Qaboos Universities
}

The current research aims to study the effectiveness of a counseling program based on Mindfulness in increasing concentration of attention and Reduce psychological stress among the general secondary stage. To achieve this goal, a counseling program has been developed that depended on activities that promote Mindfulness, in addition to a measure of Mindfulness, a measure of attention and a measure of psychological stress. The participants in this study were 74 students; It was divided into two groups. Experimental group (EG) consisted of 36 students while the control group (CG) consisted of 38 students. An experimental pretest and posttest control-group design was used in this study. The Mindfulness activates was conducted to the experimental group during the actual lesson period for 12 weeks with 50 minute sessions conducted three times a week. The results concluded that there are statistically significant differences between the pre and post measurements of the experimental group in both the dimensions of mindfulness and the total degree, as well as the level of attention in favor of the post measurement, while there were no statistically significant differences between the pre and post measurements of the experimental group in the degrees of the measure of psychological stress. The results also found that there were statistically significant differences between the experimental and control groups in both the dimensions of Mindfulness and the total degree, as well as the level of attention in favor of the experimental group, while there were no statistically significant differences between the experimental and control groups in the degrees of the measure of psychological stress. The researcher recommends support classroom and non-classroom activities. That increases the level of Mindfulness due to its importance in reinforcement of cognitive functions represented in attention to its main role in raising the level of academic achievement, and Reduce psychological stress.

Keywords. Counseling program - Mindfulness - attention - psychological stress - general secondary stage.

1 eladladel@gmail.com / adeleladl@squ.edu.om mobile, 00201145599842,0096871724290 
The effectiveness of a counseling program based on Mindfulness in increasing concentration of attention and Reduce psychological stress among the general secondary stage

\author{
Prof. Adel M. ElAdl ${ }^{2}$ \\ Prof. of Educational Psychology \\ Faculty of Education - Zagazeg \&Sultane Qaboos Universities
}

\title{
Introduction
}

The Oxford dictionary (2014) defines mindfulness as "a mental state achieved by focusing one's awareness on the present moment while calmly acknowledging and accepting one's feelings, thoughts, and bodily sensations". Mindfulness often refers to specific practices used to focus a person's attention - meditation, yoga, breathing, single-pointed concentration on an object - and is characterized by intentionality and nonjudgmental observation of experience (Broderick \& Jennings, 2012). Mindfulness is often associated with Eastern spirituality, but mindfulness' purely secular applications have been increasingly explored in settings as varied as the workplace, correctional facilities, and educational institutions.

Formal education can be challenging and stressful for all students. Students at every level - elementary school, middle school, high school, undergraduate universities and colleges, and graduate and professional studies - face similar challenges to learning and being a part of an institution of learning. While educational institutions can be settings where wondrous learning and growth can occur, they can also play host to

negative internal states such as anxiety, isolation, and depression that may not only decrease a person's learning experience but may also lead to behaviors like violence and bullying. Educators must focus on academic outcomes and classroom material but can also promote new non-academic curriculum to create a better learning environment. Mindfulness training can be valuable for helping students be more successful learners and more connected members of an educational community.

2 eladladel@gmail.com / adeleladl@squ.edu.om mobile, 00201145599842,0096871724290

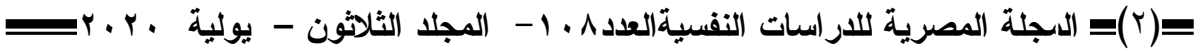


The United States Centers for Disease Control reports that $11 \%$ are diagnosed with attention deficit/hyperactivity disorder or ADHD (2014). Students with learning disabilities can have considerable obstacles in educational settings. Not only can their disabilities pose challenges to learning, but their disabilities can also make it more difficult to behave according to the conventional standards of a school. Research has shown that mindfulness can have a positive impact on students with learning disabilities. Symptoms of ADHD like frequent mind- wandering and difficulty concentrating can create obvious academic problems for students in the classroom and as they work on their studies at home. Educators who have implemented mindfulness training for students with ADHD have seen academic improvement as well as a decrease in behavioral issues arising from impulsiveness and difficulty reading social cues (Docksai, 2013). Other research has shown instruction in mindfulness benefits individuals who fall along the autism spectrum: incidents of challenging, disruptive, and overly physical behavior were reduced as individuals learned to better control their reactions to stressful situations (Thomas, 2013).

\section{Statement of the Problem}

Trait mindfulness has been described as an inherent capacity for awareness of the present without judgment of that experience; all people have it to some degree (Kabat- Zinn, 1990). Although individuals without training in contemplative practices may possess latent mindfulness, most individuals improve their level of state mindfulness through habitual practice and training (Baer, 2003; Brown \& Ryan, 2003; Bishop et al., 2004). The two components thought to be most essential in mindfulness are the ability to (i) focus on the present and (ii) use non-judgmental appraisal of one's thoughts and actions (Baer, 2003; Bishop et al., 2004; Grossman, Niemann, Schmidt, \& Walach, 2004; Holzel et al., 2011). Specifically, thoughts, feelings and sensations are observed and accepted as existing, without appraisal or classification (Baer, 2003; Bishop et al., 2004). These two conditions of mindfulness may act as a protective buffer against maladaptive coping mechanisms that arise under conditions of stress-for instance, avoidance, suppression, and obsessive thoughts (Keng et al., 2011). These components are also assumed to be part of both state and trait mindfulness. Trait mindfulness has been associated with positive life outcomes, including mental and physical health, social relationships, and life satisfaction (Brown et al., 2007). Thus the present study addresses the following questions.

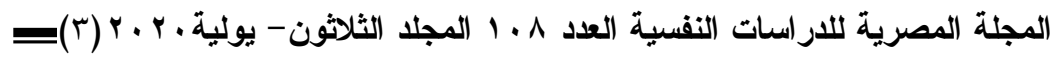


1- Are there differences in post-test scores mean between control and experimental groups on attention scale?

2- Are there differences in post-test scores mean between control and experimental groups on psychological stress scale?

3- Are there differences in pre- post-test scores mean of the experimental group on attention scale?

4-Are there differences in pre- post-test scores mean of the experimental group on Academic psychological stress?

\section{Purpose of the study}

This study aims to investigate the effectiveness of a counseling program based on Mindfulness in increasing concentration of attention and reduce psychological stress among the general secondary stage. By gaining a better understanding of this process, teachers can apply the findings to create safe, stress-free classrooms that will engage the minds of students that increase the level of Mindfulness due to its importance in reinforcement of cognitive functions represented in attention to its main role in raising the level of academic achievement, and Reduce psychological stress.

\section{Literature Review}

Attention deficit hyperactivity disorder (ADHD) most often diagnosed in childhood, but in some cases, the symptoms may persist from childhood to adulthood. ADHD is a neurodevelopmental disorder that is mostly diagnosed in childhood. This symptom includes inattention, hyperactivity and impulsivity, and disorganization, which negatively affects the performance abilities and accomplishment of individual and social duties and tasks (Kessler, Chiu, Demler, Merikangas, \& Walters, 2005; Miller, Ho, \& Hinshaw, 2014; Mosalanejad, Mosalanejad, \& Lashkarpour, 2013). Perhaps, in half of the children with ADHD symptoms, this disorder appears in adulthood (Ivanov \& Yehuda, 2014; Klein et al., 2012). ADHD occurs in $3-7 \%$ of schoolage children and 4\% of adults (Faraone \& Antshe, 2008; Kavakci, Kugu, Semiz, Meydan, Karsikaya, \& Dogan, 2012).

ADHD symptoms in adults may vary from children. Adults with this disorder are more likely than their peers to have low levels of social adjustment, difficulty in time management, poor communication skills and interpersonal skills, attention deficit disorder, executive action, impulsivity,

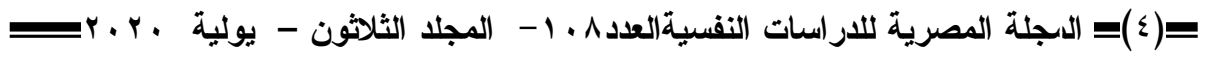




\section{-Prof : Adel M. Eladl}

emotional and psychological problems, drug abuse and drinking alcohol, of education and work challenges (Bakhshani, Raghibi, \& Babaei, 2011; Green \& Rabiner, 2016). College students with hyperactivity symptoms experience depression and educational problems during their education (Rabiner, Anastopoulos, Costello, Hoyle, \& Swartzwelder, 2008).

Stress can be described as a state of being; the body perceives something outside itself as threatening and enters a heightened state of arousal, there are several forms of stress-both beneficial and deleterious, healthy stress occurs when a stressor serves as a motivator to assist in accomplishing a task (Frydenberg, 2014). Stress is more commonly thought of in its negative form, when it is distressing and limiting to productivity and achievement. Although both forms ultimately use up energy resources, it is only adverse sources of stress that are unprofitable for the individual. Stress is a near constant across development and individuals. Early stress, and our response to it, predicts the impact of stress in young adulthood (Karatoreos \& McEwan, 2013). Although many are able to adjust and develop highly adaptive functioning in the context of stress, others do not fare as well.

\section{Method}

Research method: Quasi-experimental research method are used, quasiexperimental research is research that resembles experimental research but is not true experimental research. Although the independent variable is manipulated, participants are not randomly assigned to conditions or orders of conditions because the independent variable is manipulated before the dependent variable is measured; quasi-experimental research eliminates the directionality problem.

Participants: The sample was selected from students in the second secondary class in Egypt. The participants in this study were 74 secondary school students. Experimental group (EG) consisted of 36 students while the control group (CG) consisted of 38 students. In both groups, students' social, economic statuses, intelligence and previous scholastic achievement were nearly the same. The students' ages in both groups ranged from 16 to 17 years. The participants were selected by convenience random sampling.

The sample was randomly divided into two groups; experimental $(n=36$ boys only) and control ( $\mathrm{n}=38$ boys only). The two groups were matched on age, IQ, attention and psychological stress.

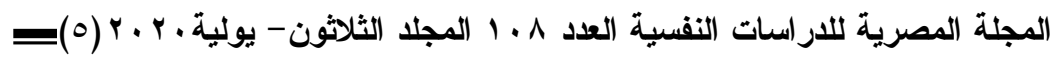


Table 1. pretest mean scores, standard deviations, $T$ - value, and significance level for experimental and control groups on age (by month), IQ, attention, and psychological stress

\begin{tabular}{|c|c|c|c|c|c|c|}
\hline Variable & Group & $\mathrm{N}$ & M & SD & $\mathrm{T}$ & Sig. \\
\hline \multirow[t]{2}{*}{ Age } & Experimental & 36 & 183.13 & 3.95 & \multirow[t]{2}{*}{0.741} & \multirow[t]{2}{*}{0.385} \\
\hline & Control & 38 & 181.91 & 3.93 & & \\
\hline \multirow[t]{2}{*}{ IQ } & Experimental & 36 & 26.48 & 6.43 & \multirow[t]{2}{*}{0.562} & \multirow[t]{2}{*}{0.627} \\
\hline & Control & 38 & 27.19 & 5.49 & & \\
\hline \multirow[t]{2}{*}{ attention } & Experimental & 36 & 31.59 & 5.81 & \multirow[t]{2}{*}{0.717} & \multirow[t]{2}{*}{0.235} \\
\hline & Control & 38 & 32.17 & 5.47 & & \\
\hline \multirow[t]{2}{*}{ stress } & Experimental & 36 & 28.12 & 7.37 & \multirow[t]{2}{*}{0.583} & \multirow[t]{2}{*}{0.513} \\
\hline & Control & 38 & 28.71 & 7.74 & & \\
\hline
\end{tabular}

\section{Data Collection tools:}

1- The Raven's Colored Progressive Matrices Test. The Raven's CPM is internationally recognized as a culture -fair or culture reduced test of nonverbal intelligence. This easily administered, multiple - choice pencil and paper test has no time limit, and comprises three sets of twelve matrix designs arranged to "assess mental development up to a stage when a person is sufficiently able to reason by analogy to adopt this way of thinking as a consistent method of inference" (Raven et al., 1993). The test is shown a series of patterns with parts missing. The parts removed are of simple shape and have been placed below the matrix. he testee can either point to the pattern piece $s /$ he has selected or write its corresponding number on the record form (Lezak, 1995). The total score is the total number of matrices completed correctly, and the test is thus scored out of 36 . The retest reliability of the Raven's CPM was revealed to be 0.88 . The degree of correlation between the Raven's CPM and the WISC revealed correlations of 0.89 .

2- Mindful Attention Awareness Scale (MAAS; Brown \& Ryan, 2003).

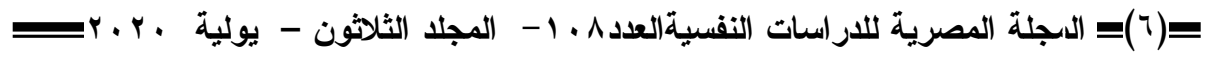




\section{Prof : Adel M. Eladl}

The MAAS was used to measure mindful awareness, or the latent ability to remain anchored in the present. The MAAS operates on a six-point scale that asks participants to rate their attentional involvement during 15 everyday experiences $(1=$ almost always to $6=$ almost never $)$-for example, "I rush through activities without being really attentive to them." The MAAS has documented adequate psychometric processes (Brown \& Ryan, 2003). For the present study, the mean MAAS score, obtained by calculating an average score across all items, was $4.00(\mathrm{SD}=.77$; range $=2.37-5.35)$. This variable was demonstrated to have a normal distribution.

3- . Adult ADHD Self-Report Scale (ASRS) This questionnaire was constructed by Kessler et al. (2005) and consists of 18 items and two parts; the first part (6 questions) is used to screen adult ADHD. The scoring method is Likert scale and it is graded from never to very often. The questionnaire has a sensitivity of $68.7 \%$ and a kappa coefficient of 0.76 . Adler, Spencer, Faraone, Kessler, Howes, Biederman, and Secnik (2006) reported high internal consistency and high concurrent validity of the questionnaire. Mokhtari, Rabiei and Salimi (2015) in Iran, also reported its correlation with the Conner- $\mathrm{s}$ ADHD questionnaire, which is 0.67 , and its validity has been obtained using confirmatory factor analysis method.

\section{4- Perceived Stress Scale}

This scale is used to measure as to what range situations in a person's life are perceived as stressful. It was developed by Cohen S., Kessler R. C., Gordon L. (1995) as a self-report scale. High scores represent high levels of perceived stress. There is a 7-reverse item in this scale. The Turkish version of the scale was adapted and validated by Eskin, Harlak,

Demirkıran, and Dereboy. (2013). In the Turkish adaptation study of the scale, the factor analysis resulted in two factors: perceived insufficient selfefficacy and perceived stress/distress. The explanatory factor analysis explains $46.5 \%$ variance. Item factor loads for perceived insufficient selfefficacy factor items ranged from 0.44 to 0.76 . Item factor loads for items perceived stress/distress ranged from 0.28 to 0.75 . The Cronbach's alpha coefficient for the scale came to 0.85 . The test-retest reliability coefficient was 0.86 . In this study, the Cronbach's alpha coefficient for the entire scale came to 0.73 .

Experimental Design

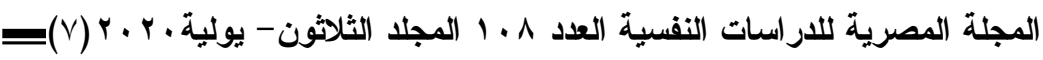


An experimental Pretest-Posttest Control-Group design was used in this study. In this design, two groups are formed by assigning (36) of the students to the experimental group and (38) to the control group. Students in the experimental and control groups were pretested and post tested in the same manner and at the same time in the study. The bivalent independent variable was the counseling program based on Mindfulness and it assumed two values: presence of the counseling program based on Mindfulness (for the experimental group) versus absence of the counseling program based on Mindfulness (for the control group). The dependent variables were the gains in scores on level of attention and psychological stress scales from the pretest and posttest.

\section{Mindfulness-Based Interventions}

In recent years, numerous mindfulness-training formats have been conceptualized. One of the first tasks in developing the training was to analyze existing formats with regard to their suitability to serve the objectives of the proposed intervention. This analysis was predicated on seven criteria elaborated by the research team for a more detailed discussion of the process. The MBI to be chosen should

(1) be empirically tested and validated;

(2) be multiple-week-long with daily individual practice as well as one longer session to account for the need of a regular meditation practice to induce physiological changes (Carmody \& Baer, 2008);

(3) have a clear focus on mindfulness meditation instead of multiple/other meditation techniques, e.g., transcendental meditation;

(4) contain mostly exercises and practices that include experience-based knowledge and are highly applicable to and integrable into participants dayto-day-life (daily-life focus);

(5) provide the possibility for thematic combination of meditation practice with the topic of sustainable consumption.

(6) incorporate both cognitive and affective training units for key competencies that are deemed relevant to an experienced meditation teacher (Ericson et al., 2014; Fischer \& Barth, 2014)

(7) be specific to the project target groups secondary school students.

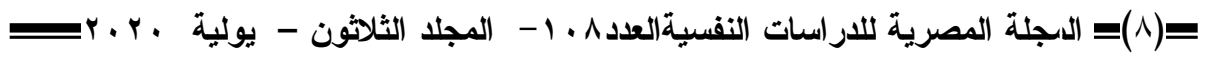




\section{-Prof : Adel M. Eladl}

\section{Procedures}

Pre-intervention testing: All the Seventy-four students in the second year of secondary school in Egypt completed The Raven's Colored Progressive Matrices Test, which assesses students' intelligence; attention scale, which assesses students' level of attention, psychological stress scale, which assesses psychological stress. Additionally, the end-of- Semester assesses attention and psychological stress results of the participants in, and provided the summative evaluation scores for the analysis. Hence, scores in the measures of students'. Thus data was reported for the students who completed the study.

General Instructional Procedures: The counseling program based on Mindfulness was conducted to the whole class by their actual teacher during the actual lesson period for 10 weeks with 45 minute sessions conducted two times a week. The program was designed based on the basic fundamentals of Mindfulness, namely dimensions (motivation regulation, effort regulation, planning, attention focusing, using additional resources, summarizing strategy, emphasis strategy, and self-direction. In the 'orchestrated immersion' phase, the students, with the help of their teacher, used various pictures, power- point presentations, cartoons and comic strips. These helped them the concepts presented and the subject matter as a whole as well. As for 'relaxed alertness,' phase, cooperative learning was present. Students collaborated with one another. Students were asked to write down, share and discuss with their classmates. The aim was to eliminate fear in the learners while maintaining highly challenging environments. During the 'active processing' phase, the learner was allowed to consolidate and internalize information by actively processing it. Simulations, group discussions, role plays and dramatization techniques were used in order to ensure the retaining of the obtained knowledge and to ease the structuring of this knowledge as well as applying it into new situations.

\section{Data Analysis}

A two-groups pre-post design was used to attention and psychological stress before and after the intervention. T-test was conducted. At each time point (pre/post), the mean and standard deviation were used to summarize group responses .Probability levels of 0.05 or smaller indicated significant differences between the experimental and control groups means. The data collected through the pre-test and post-test were entered into Statistical Package for Social Sciences (SPSS) version 23. Results

It was hypnotized that there were differences in post-test scores mean

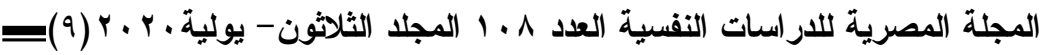


between control and experimental groups on attention Test. Table 2. shows $\mathrm{T}$. Test results for the differences in post- test mean scores between experimental and control groups in attention According to table 2., there has been found a significant difference the differences in post- test mean scores between experimental and control groups in attention $(t=8.39, p=0.00$; $\mathrm{p}<0.01$ ) in favor of the experimental group.

Table 2. T. test results for the differences in post- test mean scores between experimental and control groups in attention

\begin{tabular}{|lllll|}
\hline Test & & & & \\
& & & & \\
& Experimental & Control & T & Sig. \\
\hline attention & 36.67 & 32.53 & $8.39^{* *}$ & 0.01 \\
\hline
\end{tabular}

Note: $* * \mathrm{P}<0.01$

The second hypothesis was that there were differences in post-test scores mean between control and experimental groups on psychological stress Test. Table 3. shows $T$. Test results for the differences in post- test mean scores between experimental and control groups in psychological stress. According to table 3 ., there has been found a significant difference the differences in post- test mean scores between experimental and control groups in psychological stress $(\mathrm{t}=\mathbf{7 . 5 8}, \mathrm{p}=0.00 ; \mathrm{p}<0.01)$ in favor of the experimental group.

Table 3. T. test results for the differences in post- test mean scores between experimental and control groups in psychological stress.

\begin{tabular}{|llllll|}
\hline Test & & & & \\
& & & & \\
\hline & Experimental & Control & T & Sig. \\
\hline psychological stress & 33.38 & 28.81 & $7.58 * *$ & 0.01 \\
\hline
\end{tabular}

Note: $* * \mathrm{P}<0.01$

The third hypothesis was that there were there differences in pre- post-test scores mean of the experimental group on attention Test. Table 4. shows T. Test results for the differences in pre- post-test scores mean of the experimental group on attention test. According to table 4., there has been

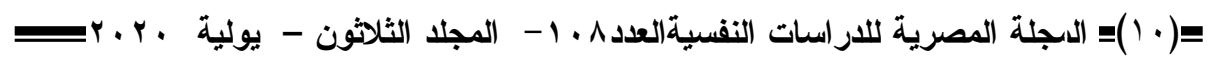




\section{Prof : Adel M. Eladl}

found a significant difference the differences in pre- post-test scores mean of the experimental group on attention $(\mathrm{t}=6.97, \mathrm{p}=0.00 ; \mathrm{p}<0.01)$ in favor of post-test scores mean

Table 4. T. test results for the differences in pre-post-test scores mean of the experimental group on attention Test

\begin{tabular}{|lllll|}
\hline & Post-test & Pre-test & T & Sig. \\
\hline attention & 36.67 & 32.17 & $6.97 * *$ & 0.000 \\
\hline
\end{tabular}

Note: $* * \mathrm{P}<0.01$

The fourth hypothesis was that there were there differences in pre- post-test scores mean of the experimental group on psychological stress test. Table 5. shows $\mathrm{T}$. Test results for the differences in pre- post-test scores mean of the experimental group on psychological stress Test. According to table 5., there has been found a significant difference the differences in pre- post-test scores mean of the experimental group on psychological stress $(t=7.89, p=$ $0.00 ; \mathrm{p}<0.01)$ in favor of post-test scores mean.

Table5. T. test results for the differences in pre-post-test scores mean of the experimental group on psychological stress Test

\begin{tabular}{|lllll|}
\hline & Post-test & Pre-test & T & Sig. \\
\hline psychological stress & 33.38 & 28.71 & $7.89 * *$ & 0.000 \\
\hline
\end{tabular}

Note: $* * \mathrm{P}<0.01$

\section{Discussion}

Because mindfulness does seem to have a relevant and potentially important role in education, mindfulness instruction probably should be incorporated into curriculum at all levels of education to help students be more successful. Mindfulness education appears to have a positive impact on academic performance by helping students - even those with learning disabilities focus, be more organized, plan ahead, perform better on exams, and think critically. Students trained in mindfulness are more likely to behave according to a school's standards; schools have even seen dramatic behavior problems like bullying decrease with the implementation of mindfulness instruction. Students in people-centered, emotionally-taxing programs of study like medicine and social work are better able to serve their clients and take care of themselves when mindfulness is incorporated into their

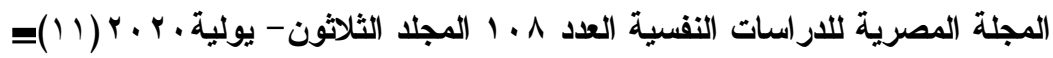


curriculum. Research on mindfulness in education shows its usefulness at all ages and grade levels, from elementary school to middle school to high school to undergraduate studies to graduate and professional degree programs. In an era of dwindling funding for schools, introducing new curriculum is seldom an easy undertaking; however, mindfulness training can be free or at least inexpensive, and it can be incorporated into existing classes or established as stand-alone classes. The benefits of mindfulness can be realized in the other aspects of students' lives with improved skills in focus, problem-solving, impulse control, relationship-building, and stress reduction.

\section{Conclusions}

This study goes some way to understanding attention and psychological stress among the general secondary stage. The study shows that students in the experimental group, compared to those in the control group, develop level of attention and Reduce psychological stress. due to training in counseling program based on Mindfulness. The study shows that those students have great chance of developing their level of attention and Reduce psychological stress

\section{Future Research and Recommendations}

More research in mindfulness would be useful to guide the discussion about how it can be implemented with the greatest impact on students. Research could focus on the various approaches to mindfulness (meditation, yoga, etc.) to determine which are most effective and may find that different groups benefit more from one approach versus another. Other academic and professional programs that train students in careers involving high interpersonal interaction and stress could apply the lessons learned from social work and medical students; teachers, nurses, attorneys, law enforcement professionals, and those working in business management could begin their careers better equipped to handle difficult situations and maintain a healthy emotional outlook as a complement to the technical skills formal education provides. Coaches of team sports could use mindfulness to help teammates work together more collaboratively instead of competing amongst themselves. In summary, mindfulness may be an effective tool to mold students into better learners

and educational institutions into better learning communities.

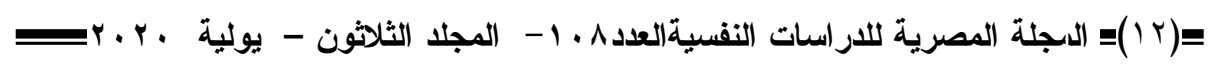




\section{References}

Adler, L. A., Spencer, T., Faraone, S. V., Kessler, R. C., Biederman, J., \& Secnik, K. (2006). Validity of pilot adult ADHD self-report scale (ASRS) to rate adult ADHD symptoms. Annals of Clinical Psychiatry, 18(3), 145-148. doi: $10.1080 / 10401230600801077$.

Baer, Ruth A. (2003). Mindfulness training as a clinical intervention: A conceptual and empirical review. Clinical Psychology: Science and Practice, 10(2), 125-143. doi:10.1093/ clipsy/bpg015.

Bakhshani, N., Raghibi, M., \& Babaei, S. (2011). Prevalence of adulthood attention deficit / hyperactivity symptoms in students of Sistan and Balouchestan University. Zahedan Journal Research in Medical Science (ZJRMS), 13(7), $18-22$.

Biederman, J., Mick, E., Faraone, S.V., Braaten, E., Doyle, A., Spencer, T., \& Johnson, M. A. (2002). Influence of gender on attention deficit hyperactivity disorder in children referred to a psychiatric clinic. American Journal of Psychiatry, 159, 36-42. doi:10.1176/appi.ajp.159.1.36.

Bishop, S. R., Lau, M., Shapiro, S., Carlson, L., Anderson, N. D., Carmody, J., . . . Devins, G. (2004). Mindfulness: A proposed operational definition. Clinical Psychology: Science and Practice, 11(3), 230-241. doi:10.1093/clipsy/bph077

Broderick, P., \& Jennings, P. (2012). Mindfulness for adolescents: A promising approach to supporting emotion regulation and preventing risky behavior. New Directions For Youth Development, 2012(136), 111-126.

Brown K. W., Ryan R. M (2003). The benefits of being present: Mindfulness and its role in psychological well-being. Journal of personality and Social Psychology 84: 822848.

Brown, K. W., Ryan, R. M., \& Creswell, J. D. (2007). 
Mindfulness: Theoretical foundations and evidence for its salutary effects. Psychological Inquiry, 18(4), 211-237. doi:10.1080/10478400701598298.

Carmody, J., \& Baer, R. A. (2008). Relationships between mindfulness practice and levels of mindfulness, medical and psychological symptoms and well-being in a mindfulness-based stress reduction program. Journal of Behavioural Medicine, 31(1), 23-33. https://doi.org/10.1007/s10865-007-9130-7

Centers for Disease Control and Prevention. (2014). Attentiondeficit/hyperactivity Disorder (ADHD) data and statistics. Retrieved from http://www. cdc.gov/ncbddd/adhd/data.html.

Cohen S., Kessler R. C., Gordon L. (1995). Measuring Stress: A Guide for Health and Social Scientists, New York, Oxford University Press Inc.

Docksai, R. (2013). A mindful approach to learning. Futurist, $47(5), 8-10$.

Eskin M., Harlak H., Demirkiran F., Dereboy C. (2013). The adaptation of the perceived stress scale into Turkish: a reliability and validity analysis. New Symp Journal, 51, 132-140.

Ericson, T., Kjønstad, B. G., \& Barstad, A. (2014). Mindfulness and sustainability. Ecological Economics, 104, 73-79. https://doi.org /10.1016/j.ecolecon.2014.04.007

Faraone, S. V. \& Antshe, K. M. (2008). Diagnosing and treating attention-deficit/hyperactivity disorder in adults. World Psychiatry, 7(3), 131-136.

Fischer, D., \& Barth, M. (2014). Key competencies for and beyond sustainable consumption: An educational contribution to the debate. GAiA, 23(S1), 193- 200. https://doi.org/10.14512/gaia .23.S1.7

Frydenberg, E. (2014). Coping research: Historical background,

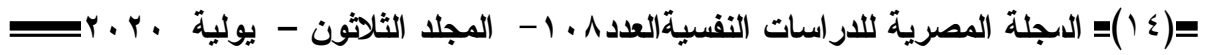


links with emotion, and new research directions on adaptive processes. Australian Journal of Psychology, 66, 82-92. doi:10.1111/ajpy.12051

Green, A. L., \& Rabiner, D. L. (2016). What do we really know about adhd in college students? Neurotherapeutics, 9, 559568. doi: 10.1007/s13311-012-0127-8.

Grossman, P., Niemann, L., Schmidt, S., \& Walach, H. (2004). Mindfulness-based stress reduction and benefits: A metaanalysis. Journal of Psychosomatic Research, 57, 35-43. doi:10.1016/S0022-3999(03)00573-7.

Holzel, B., Lazar, S., Gard, T., Shuman-Olivier, Z., Vago, D., \& Ott, U. (2011). How does mindfulness meditation work? Proposing mechanisms of action from a conceptual and neural perspective. Perspectives on Psychological Science, 6(6), 537-559. doi:10.1177/1745691611419671

Ivanov, I. \& Yehuda, R. (2014). Optimizing fitness for duty and post-combat clinical services for military personnel and combat veterans with ADHD: A systematic review of the current literature. European Journal of Psychotraumatology, 5, 1-11. doi: 10.3402/ejpt.v5.23894.

Kabat-Zinn, J. (1990). Full catastrophe living: Using the wisdom of your body and mind to face stress, pain and illness. New York, NY: Delacorte.

Karatoreos, I., \& McEwen, B. (2013). Annual research review: The neurobiology and physiology of resilience and adaptation across the life course. Journal of Child Psychology and Psychiatry, 54(4), 337-347. doi:10.1111/jcpp.12054

Kavakci, O., Kugu, N., Semiz, M., Meydan, F., Karsikaya, S., \& Dogan, O. (2012). Prevalence of attentiondeficit/hyperactivity disorder and co-morbid disorders among students of Cumhuriyet University. European Journal of Psychiatric, 26(2), 107-117. doi: $10.4321 / \mathrm{S} 0213-61632012000200004$

Keng, S., Smoski, M., \& Robins, C. J. (2011). Effects of

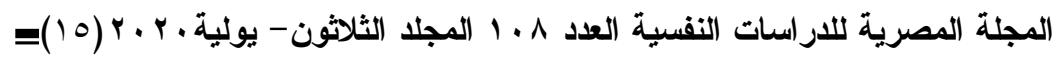


mindfulness on psychological health: A review of empirical studies. Clinical Psychology Review, 31, 10411056. doi:10.1016/j.cpr.2011.04.006

Kessler, R. C., Adler, L. A., Barkley, R., Biederman, J., Conners, C. K., Faraone, S. V., \& et al. (2005). Patterns and predictors of attention-deficit/hyperactivity disorder persistence into adulthood: Results from the national comorbidity survey replication. Biological psychiatry, 57(11), 1442-1451. doi:10.1016/j.biopsych.2005.04.001.

Kessler, R. C., Chiu, W. T., Demler, O., Merikangas, K. R., \& Walters, E. E. (2005). Prevalence, severity, and comorbidity of 12-month DSM-IV disorders in the National Comorbidity Survey Replication. Archives of General Psychiatry, 62, 617-627. doi: 10.1001/archpsyc.62.6.617.

Klein, R. G., Mannuzza, S., Olazagasti, M. A. R., Roizen, E., Hutchison, J. A., Lashua, E. C., \& et al. (2012). Clinical and functional outcome of childhood attention deficit/hyperactivity disorder 33 years later. Archives of General Psychiatry, 69, 1295- 1303. doi: 10.1001/archgenpsychiatry. 2012.271.

Lezak, M. D. (1995). Neuropsychological assessment (3 ${ }^{\text {rd }}$ - ed.). Oxford University Press.

Miller, M., Ho, J., \& Hinshaw, S. P. (2014). Executive Functions in Girls With ADHD Followed Prospectively Into Young Adulthood. Neuropsychology, 26(3), 278-287. doi: 10.1037/a0027792.

Mindfulness. (2014). In Oxford dictionaries online. Retrieved from

http://www.oxforddictionaries.com/us/definitio n/american_english/mindfulness.

Mokhtari, H., Rabiei, M., \& Salimi, S. H. (2015). Psychometric properties of the Persian version of adult attention-deficit/hyperactivity disorder self-report scale. Iranian Journal of Psychiatry and Clinical Psychology, 21

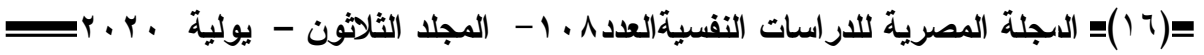


(3), 244-253.

Mosalanejad, M., Mosalanejad, L., \& Lashkarpour, K. (2013). Prevalence of ADHD among students of Zahedan University of medical science in Iran. Iranian Journal of Psychiatry and Behavioral Sciences, 7(2), 83-90.

Rabiei and Salimi (2015). Adjustment to college in students with ADHD. Journal of Attention Disorder, 11(6), 689-99. doi:10.1177/ 1087054707305106.

Rabiner, D. L., Anastopoulos, A. D., Costello, J., Hoyle, R. H., \& Swartzwelder, H. S. (2008). Adjustment to college in students with ADHD. Journal of Attention Disorder, 11(6), 689-99. doi:10.1177/1087054707305106.

Raven, J. C., Court, J.H. \& Raven, J.C. (1993). Manual for Raven's Progressive Matrices and Vocabulary Scales Section 1: General Overview. Oxford: Oxford Psychologists Press

Thomas, C. (2013). Role of mindfulness in reducing challenging behaviour. Learning Disability Practice, 16(10), 33-37. 


\title{
فعالية برناهج ارشادي قائم على اليقظة العقلية في زيادة \\ تركيز الانتباه وتخفيف حدة الضفوط النفسية بالمرحلة \\ الثانوية العاهمة
}

\author{
دكتور/ عادل محمد العدل \\ أستاذ علم النفس التربوي
}

كلية التزبية - جامعة الزقازيق

يهدف البحث الحالي الى دراسة فعالية برنامج ارشادي قائم على اليقظة العقلية في زيادة تركيز

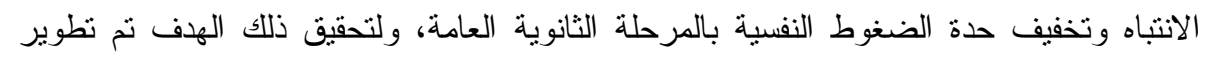

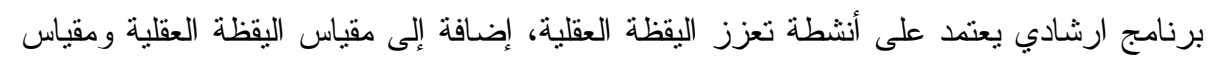

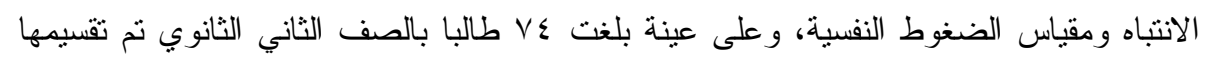

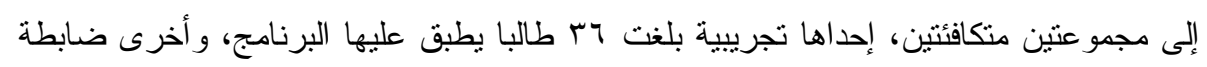

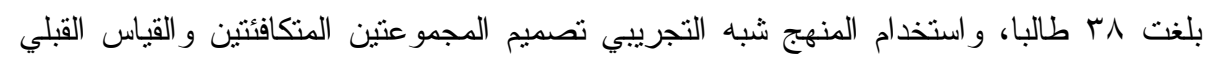

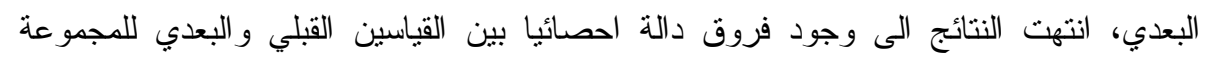
التجريبية في كل من أبعاد اليقظة العقلية والدرجة الكلية وكذلك مستوى الانتباه لصالح القياس القياس

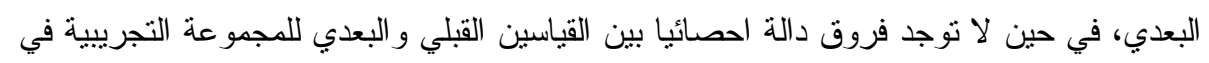

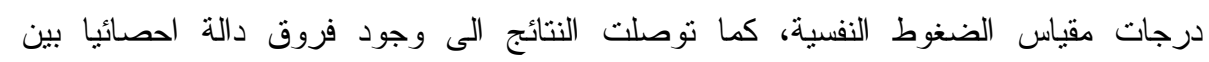
المجموعتين الضابطة والتجريبية في القياس البعدي لكل من أبعاد اليقظة العقلية و الدرجة الكلية

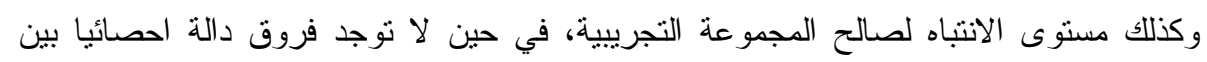

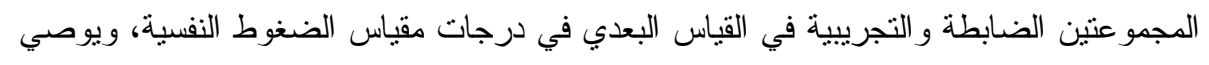

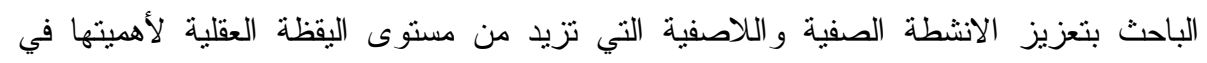

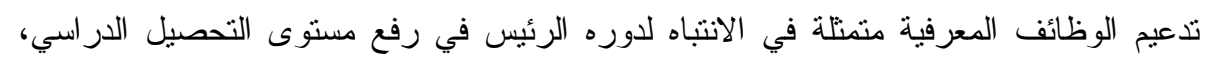
وخفض مستوى الضغوط النفسية. الكلمات المفتاحية: برنامج ارشادي - اليقظة العقلية - الانتباه - الضغوط النفسية - المرحلة الثانوية العامة.

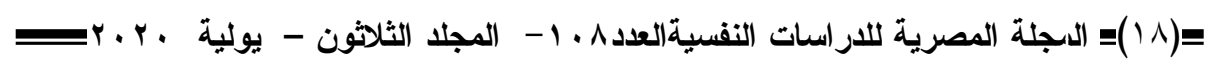

